\title{
EARTH-TO-ORBIT ROCKET PROPULSION
}

\author{
${ }^{\ddagger}$ André Beaurain and ${ }^{\S}$ Alain Souchier \\ Large Liquid Propulsion Division, Snecma Moteurs, Vernon, France \\ IMichel Moravie, Snecma Propulsion Solide, Bordeaux, France \\ *Robert Sackheim \\ NASA Marshall Space Flight Center, Huntsville, Alabama USA \\ ${ }^{\dagger}$ Harry A. Cikanek III \\ NASA Glenn Research Center, Cleveland, Ohio USA
}

\begin{abstract}
The Earth-to-orbit (ETO) phase of access to space is and always will be the first and most critical phase of all space missions. This first phase of all space missions has unique characteristics that have driven space launcher propulsion requirements for more than half a century. For example, the need to overcome the force of the Earth's gravity in combination with high levels of atmospheric drag to achieve the initial orbital velocity; i.e., Earth parking orbit or $\approx 9 \mathrm{~km} / \mathrm{s}$, will always require high thrustto-weight (T/W) propulsion systems. These are necessary with a T/W ratio greater than one during the ascent phase. The only type of propulsion system that can achieve these high T/W ratios are those that convert thermal energy to kinetic energy. There are only two basic sources of onboard thermal energy: chemical combustion-based systems or nuclear thermal-based systems (fission, fusion, or antimatter). The likelihood of advanced open-cycle, nuclear thermal propulsion being developed for flight readiness or becoming environmentally acceptable during the next century is extremely low. This realization establishes that chemical propulsion for ETO launchers will be the technology of choice for at least the next

*Assistant Director and Chief Engineer for Propulsion, Fellow AIAA †Chief, Space Transportation Projects Office

¥Advanced Liquid Rocket Engine Technology Leading Engineer

${ }^{\S}$ Future Programs and European Cooperation Manager, AIAA Member ISolid Propulsion Future Programs Manager

Copyright 02003 by the American Institute of Aeronautics and Astronautics, Inc. No copyright is asserted in the United States under Title 17, U.S. Code. The U.S. Government has a royalty-free license to exercise all rights under the copyright claimed herein for Governmental Purposes. All other rights are reserved by the copyright owner.
\end{abstract}

century, just as it has been for the last half century of rocket flight into space.

The world's space transportation propulsion requirements have evolved through several phases over the history of the space program, as has been necessitated by missions and systems development, technological capabilities available, and the growth and evolution of the utilization of space for economic, security, and science benefit. Current projections for the continuing evolution of requirements and concepts may show how future space transportation system needs could be addressed. The evolution and projections will be described in detail in this manuscript.

\section{INTRODUCTION}

Liquid-propellant rocket engines have been shown to have a very long period between the start of their development and the end of their operational lifetime, particularly if one recognizes their successive evolutionary versions. These total lifetimes can reach 30 years or more. If we include the development time of elementary technologies, we can add an extra 10-year period. In other words, the technologies which are just now being developed will still be used in 2040! These days, development periods tend to be shortened from 10 to 5 years because the development processes are prepared by maturing of technologies. This includes system-level technological demonstrations at a scale that is representative of the final product, but the total lifetime of the technology is minimally affected.

Engines currently being developed are now benefitting from research, technology, and development activities that were initiated in the 1980's. However, most of these activities are applicable to engines currently in operational 
service rather than to future development activities. The analytical codes resulting from these activities are often applied to processing of production waivers of anomalies occurring during ground acceptance tests on flight equipment or in flight performance. It is also very important to recognize that research and technology activities maintain and increase the skills of the teams whose technical skills and capabilities are vital in solving the problems that are still experienced in the operational stages.

\section{THE ENGINE SYSTEM}

Considering the engine as a whole system, research activities start with functional studies to define the operational parameters and the thermodynamic/power cycle to be used. The engine specifications are derived from the launcher specifications and from a first definition of the launcher linked to mission choices (target orbit, payload weight) and from such considerations as reliability, operability, maintainability, and cost. It is also at this stage that fundamental design and operations criteria have to be applied, such as whether to reuse the launcher, and therefore its engine, or keep to traditional solutions where the launcher and the engine are expendable.

These engine studies are used to determine the kinds of technology and know-how that will need to be available at the start of the corresponding development and therefore to initiate the preliminary research and technology programs. This system approach is, in general, combined with a technology and development approach. Specialists in various fields of technology suggest research activities for the next 5 or 10 years. The technologies that may eventually be mastered may lead to new concepts for engines, or more simply, for thermodynamic cycles, performance, design approach, etc. Future engine design activities underway at Snecma are illustrated in Fig. 1.

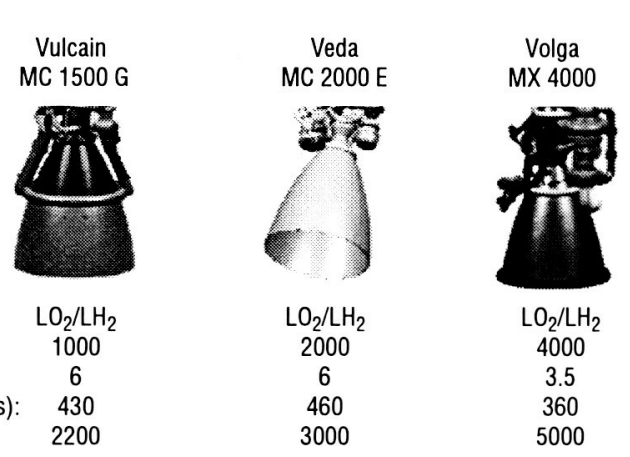

Fig. 1. Future Snecma high-thrust cryogenic engines.

\section{MATERIALS AND STRUCTURES- NEXT-GENERATION RLV PROPULSION}

Substantial advancements have been made in materials, structures, and manufacturing processes. At NASA, new high conductivity alloys have progressed to the point that the materials are now in an advanced state of development and are expected to be ready to enter fullscale development consistent with the next-generation reusable launch vehicle (RLV) schedule needs. These alloys are substantially improved over the Narloy Z utilized in the Space Shuttle main engine (SSME) main combustion chamber development, which is still the world's only demonstrated reusable liquid rocket engine.

Another major advancement was accomplished through use of silicone nitrate $(\mathrm{SiN})$ rolling elements for bearings in SSME turbomachinery, as shown in Fig. 2.

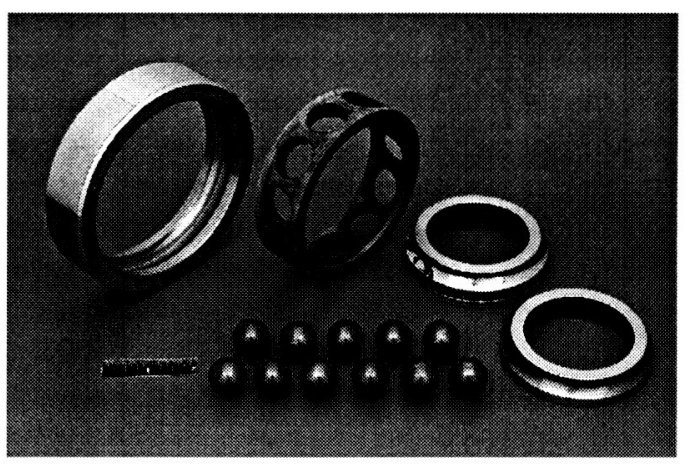

Fig. 2. SSME turbopump bearing with PTFE/ fiberglass cloth cage and SiN balls.

NASA Marshall Space Flight Center (MSFC) and the engine companies pioneered their development. The SiN bearings have been a key enabler for turbomachinery certification to 10-mission duty cycles. The life history of these bearings has been far superior to conventional designs used in older generation turbomachinery. This improvement has come with some changes in dynamics due to higher stiffness and different nonlinearities found in rotor response.

Advanced metal casting technology originated in the aeropropulsion industry during the 1980's. This technology was further advanced for space propulsion in the 1990's and has provided major advantages to today's engines, including reduction in parts, welds, and manufacturing processes, and an increased ability to verify hardware integrity. MSFC and the engine development and manufacturing companies made substantial contributions to the casting technology. These contributions were funded under the Space Transportation Main Engine and Alternate Turbopump programs in the early 1990's as a culmination to work begun in the late 
1980's under the same programs. The results are shown in today's Block II SSME (Fig. 3).

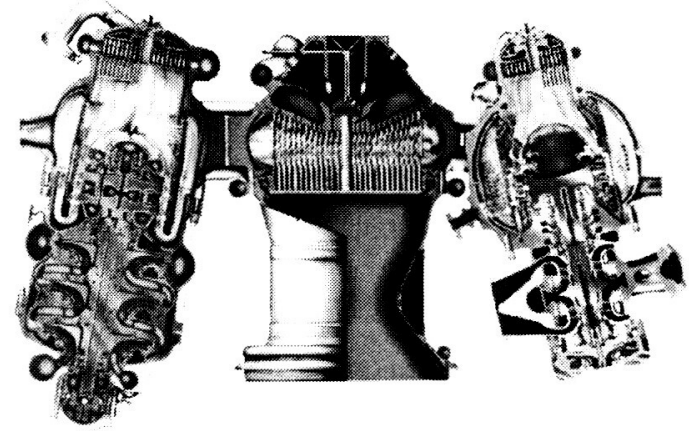

Fig 3. Block II SSME.

The turbomachinery story would not be complete without also identifying another technology brought from aeropropulsion, the single-crystal turbine blades, shown in Fig. 4. Single-crystal blades were implemented in the SSME alternate turbopumps following a substantial development effort. Another part of that effort was making significant advances in blade damping. Advances in blade damping were required to make the single-crystal technology successful. The single-crystal blades with new damping techniques have also been key contributors to the 10-mission life certification.

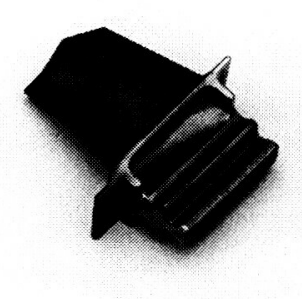

Fig. 4. SSME turbopump single-crystal blade.

Advanced bonding and buildup processes, such as liquid interface diffusion bonding, friction stir welding, and vacuum plasma spray deposition developed by MSFC and the engine companies, have begun to enable construction of combustion chambers and other components with higher reliability, lower cost, and fewer components. Advancements in powder metallurgy have made that technique practical for a broader range of uses to enable improved properties.

\section{RESEARCH AND TECHNOLOGY}

Research and technology covers a wide scope of activities. As far as "pure research" is concerned, a distinction is made between observation, analysis, and understanding the elementary physical phenomena, quantification, and digital modeling of these phenomena, up to the modeling of their combination in order to properly describe the physical macroprocess we wish to control. As an example, for rocket engine combustion physics, the topics of injection, atomization, evaporation, combustion, heat exchanges with the wall, etc., have to be addressed. The modeling performed will also have to be validated and correlated with specific experiments.

Research activities also focus on methodologies and know-how that often cut across various scientific fields (meshing methodologies, digital solvers, post-processing, fast design, and design-to-cost expert systems, etc.). Many of these methodologies are now integrated into the extension of CFD and CAD to CAD/CAM and CIM. At the system level, there are questions for which methodologies have only been worked on intensively for the last few years, such as knowledge management methodologies for development optimization (reduction of the design cycle, span time as shown in Fig. 5, the risks associated with the project, number of tests required, and operation in multidisciplinary project levels). The activities related to these macromethodologies must also be considered as part of the research process.

The fine tuning and validation of new technologies are only the tip of the iceberg. The stage of maturity reached by these technologies can be assessed with an almost universal scale - technology readiness level (TRL). The maturing of a technology to a level sufficient to safely start a development for which it is a fundamental prerequisite must go through a "technology demonstrator" stage. At this stage, the technology to be validated is applied to an object of a size comparable to that of the target object so that scale effects, if any, are well represented. Also, the integration of a technology into an actual object can highlight interactions with other technologies or operating and ambient conditions that could not have been experienced in the course of laboratory work. It is only after such a trial that the technology is truly validated and ready for use in the development of new engines.

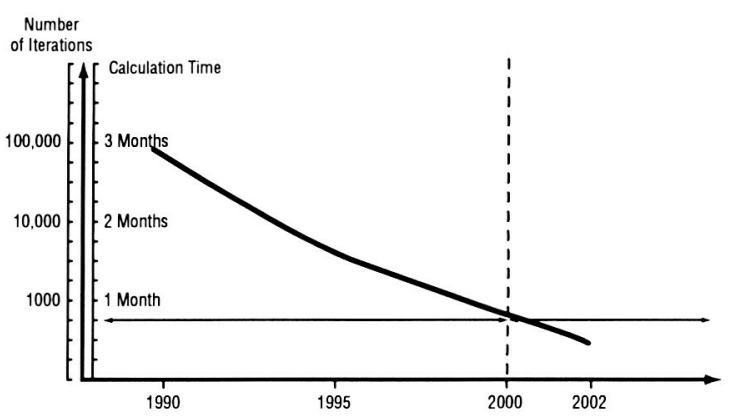

Fig. 5. Progress in reducing required modeling effort/times. 


\section{COMBUSTION AND COMBUSTION COMPONENTS}

One of the more critical parts in a rocket engine turbine power source; i.e., either a chamber preburner or gas generator, is the injector head, as it usually includes many basic injectors comprised of several parts. For liquid $\mathrm{LH}_{2}$ and $\mathrm{LO}_{2}$, coaxial injectors are elements used to inject $\mathrm{LO}_{2}$ into the center and $\mathrm{LH}_{2}$ on the fringe. Atomization is achieved by the shear forces between the liquid $\mathrm{O}_{2}$ and the mostly gaseous $\mathrm{H}_{2}$. If there is an excessive increase in flow rate for a single injector element, the combustion efficiency will likely be decreased. Recent combustion research at Snecma has shown that new injectors with three coaxial layers (referred to as "tricoax") will allow a flow rate 12 times higher than nominal with no loss in efficiency (Fig. 6). This technology combined with a simplified architecture and a body obtained by powder metallurgy offers the possibility of halving the cost of a gas generator. Other processes are aimed at producing injector plates with numerous injection holes and flow passages at a much lower cost. The current platelet technology in the U.S. is a good example. Figure 7 illustrates an example of the modeling operation of the Vulcain 3 gas generator demonstrator.

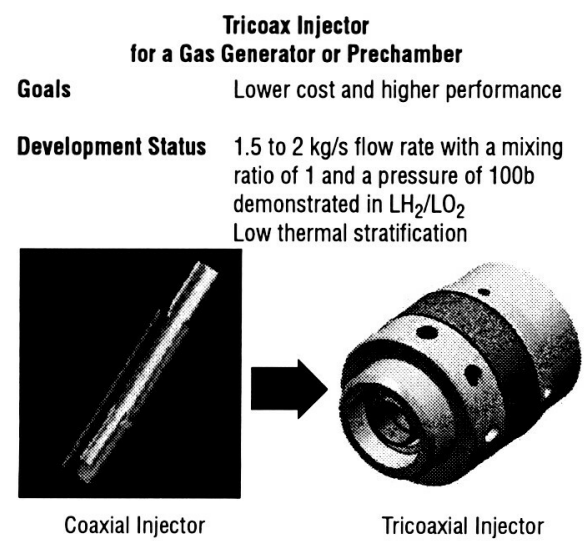

Fig. 6. Example of high flow rate injector.

Two- and Three-Dimensional Calculation of the Flame Length and the Mixture

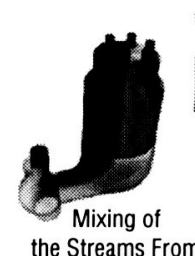

the Streams From

Six Injectors

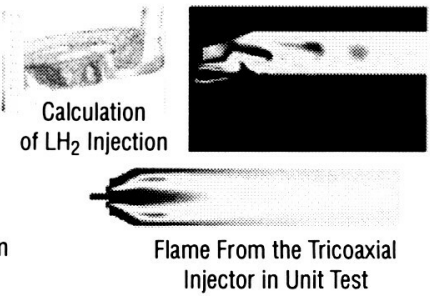

Injector in Unit Test
Fig. 7. Example of modeling operation of the Vulcain 3 gas generator demonstrator.
The combustion chamber, whose walls are regenerately cooled by propellant flow in channels, is also a costly part of a rocket engine. Technologies like highthickness plasma forming for copper-containing materials will not only cut costs by $40 \%$ but will also allow increased cooling efficiency by enabling the introduction of thermal barriers or heat exchange enhancement devices.

Downstream from the chamber, the expansion nozzle section is essential to proving the optimum performance in a space vacuum. More and more, composite materials are applied to nozzles, mainly to deployable nozzles, as shown in Fig. 8.

These deployable nozzles make it possible to reduce the required "stack-up" height of second-stage engines. A fixed divergent section would require a very high interconnecting structure between the main and the second stages, entailing considerable extra weight and additional cost for the launcher. Generally, the divergent section is deployed before the engine is switched on.

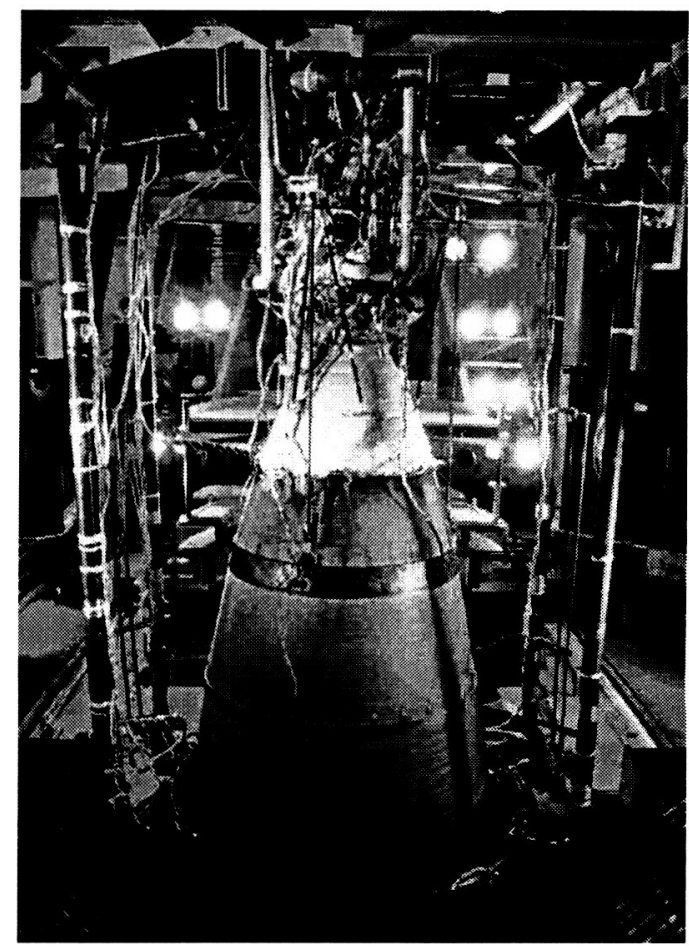

Fig. 8. Snecma composite divergent section after deployment on a Pratt and Whitney RL10 engine.

When an engine, such as the Ariane 5 Vulcain or the SSME has been running since lift-off, the size of the divergent section is limited by the allowable expansion ratio against the ambient back pressure. If the stream pressure at the divergent outlet drops below 0.2 bar, the stream will separate from the wall, as illustrated by the CFD model result in Fig. 9. This could induce vibrations, 


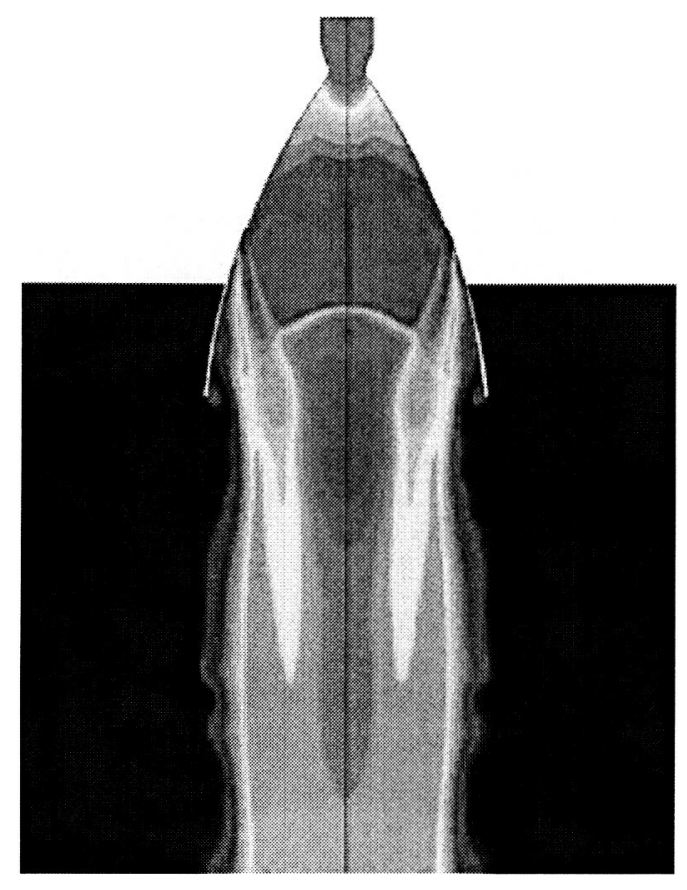

Fig. 9. Flow separation in a divergent section. Display of the temperature of a flow separation calculation on Vulcain nozzle $P t=57.75$ bar.

lateral stresses, and harmful overheating. This physical constraint also limits the engine efficiency in vacuum at the low end (near zero) of ambient pressure.

Work has been ongoing for the optimization of a large nozzle section on which the behavior of the separated stream could be controlled. This would allow both safe ignition on the ground and excellent performance in the vacuum of space.

\section{TURBOPUMPS}

The main areas for improvement in turbopumps are in reducing or eliminating pump dynamic cavitation to reduce inlet pressures and therefore the weight of the launcher's tanks; the performance of the pump impellers to reduce the number of stages at the same outlet pressure; bearings to increase the rotating speed and lifetime; turbines to increase efficiency and lifetime; and in general, reduction of manufacturing costs, particularly for housings and volutes.

The cavitation phenomena at the pump inlet are being investigated by testing in simulated fluid and by modeling in the U.S., Europe, and the former Soviet Union countries. Figure 10 shows reductions achieved in the design-cycle time for turbopump inducers that have resulted from the vast improvements in modeling capabilities and other design tools.

\section{Duration of Calculation and Design of an Inductor}

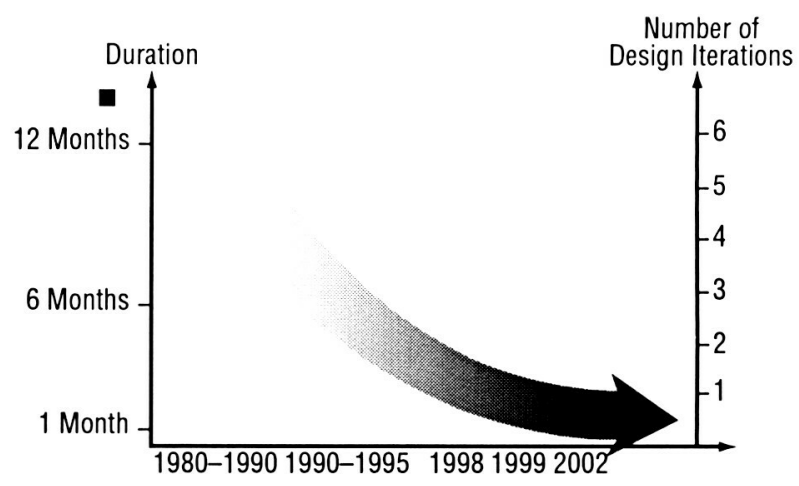

Fig. 10. Improvements in the design time for inductors over the last 20 years.

A number of successful research activities on boost pumps have been conducted in Russia with Russian, European, and American partners. These pumps, located upstream from the main turbopump, are one way of allowing very low net positive suction head (NPSH) pressures in the tanks, thereby reducing their weight. These results could well be used for future RLV designs.

For expendable engines and launchers, it is preferable to avoid paying for extra equipment by minimizing cavitation in the main turbopump. This requires that the first pump stage that serves as an inducer should run on low pressure, but it also requires controlling any dynamic instabilities that might result from interactions between the characteristics of the feedline and the pockets of gas attached to the leading edge of the inducer when operating in incipient cavitation.

The initial increase in fluid pressure comes from the inducer, but the main increase in pressure is provided by the centrifugal impeller downstream. The desired technological improvements are to increase the pressure rise across the pump. It must be maximized to enable a single pump impeller to obtain the same outlet pressure as currently provided by two impellers in series. The machine will be simpler, more reliable, lighter, and less costly. The design of the impellers' hydraulic ducts is determined by 3D Navier Stokes calculations, validated or confirmed by testing with simulated fluids (air or water).

Shrouded impellers are often drilled from a single blank, but the process is difficult and costly and limits the shapes of the flow channels. A new method, powder metallurgy, has been developed to make the impellers more efficient, especially the smaller impellers. This technology is used to produce a hydraulic duct with final net dimensions that do not require reworking, due to their highly complex shapes. The recent improvements with these advanced manufacturing processes are illustrated in Fig. 11. 
Powder Metallurgy for Pump Impellers

Goals: Cost Reduction, Improved Performance

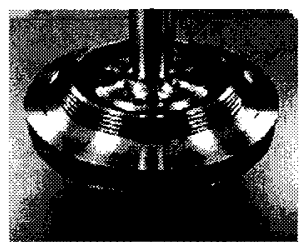

Vulcain Scale

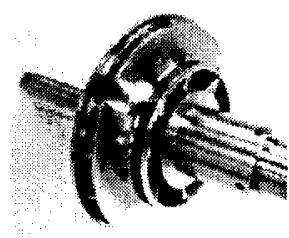

Vinci Scale
Fig. 11. The new Vinci engine is fitted with an impeller produced by powder metallurgy.

Using this new technology, the number of impeller stages for a small, high-pressure turbopump may be reduced from three to two stages. Powder metallurgy also improves the function of unshrouded impellers, allowing faster rotation and stronger pressure production. This configuration requires better control of the clearances between the impellers and the casing of the hydraulic duct and also that the axial stresses and dynamic behaviors be mastered. The production of impellers where all surfaces are easily tool accessible is also less costly.

Considerable advancements have been made over traditional ball bearings by using silicon carbide balls and stronger, more efficient materials for the bearing retainer. Retainer improvements and friction coefficient reduction in general are very important for engine bearings that are flooded in $\mathrm{LH}_{2}$ and $\mathrm{LO}_{2}$ at cryogenic temperatures when they are operating. With these new ceramic bearings, it is possible to double the speed of the balls. As a result, the turbopump layout may be simplified since the bearings can be fitted on sections of the shaft with a larger diameter. These new bearings are the product of research and technology activities, starting with the field of tribology, including very complex modeling, and completed by technological demonstrations at a representative scale, as illustrated in Fig. 12.

Performance of Large-Diameter Bearings $\times$ Rotation Speed (HDN)
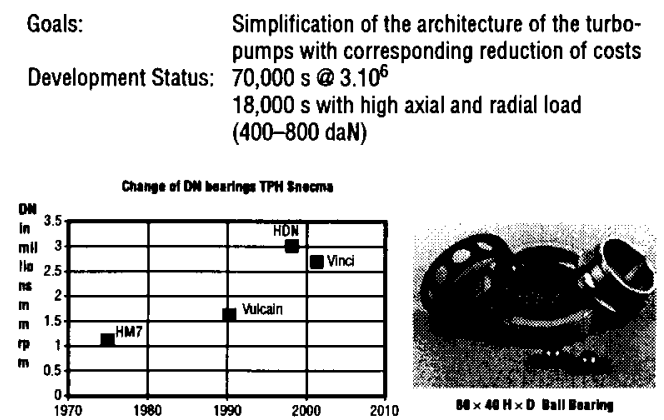

Fig. 12. Snecma TPH advanced bearing test bed used to characterize new bearing technology of future $\mathrm{LH}_{2}$ turbopumps.
Hydrostatic bearings appear to be a very good solution for increasing pump speeds. In this configuration, the shaft is supported by injection of $\mathrm{LH}_{2}, \mathrm{LO}_{2}$, or other propellants under pressure at the pump outlet.

Technologies, such as single-block manufacturing of disk and blades, are also being developed for making lowcost turbines. The turbines are currently the subject of theoretical and experimental work whose purpose is to better control disk and blade vibrations, including aerodynamic interactions, since these dynamic phenomena are likely to create difficulties during development testing.

\section{EQUIPMENT}

The various components, valves, pressure reducers, and check valves that are used to control rocket engines constitute an important part of the cost and an even more important contributor to the failure rates of such an engine.

In this area, research and technology activities also concern simplification with innovative solutions, such as immersing the electrical coil control in cryogenic fluid, as illustrated in Fig. 13. Doing this eliminates the seals for the drive shafts and reduces electrical losses.

In order to optimize the thrust over wide operating ranges, control operating life, and deal with failures

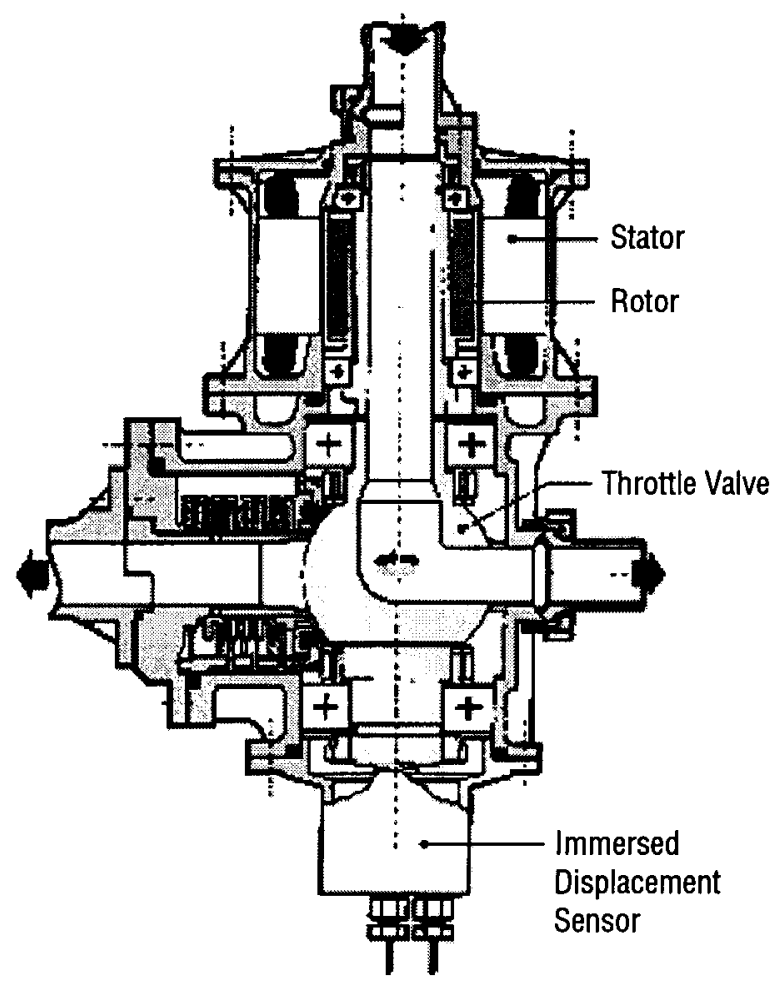

Fig. 13. Valve with actuator immersed in cryogenic propellant. 
through integrated health management of the engine during malfunctions, future RLV engines will make much greater use of regulating components than those currently in use. To do this, it is necessary to have equipment with proportional electrical control as well as microprocessors capable of withstanding a high-vibration environment induced by the engine.

In an RLV, the equipment controlling the fluids is not all located on the engine. Various control elements are used to fill and pressurize the tanks, store helium pressurant gas, regulate its pressure, and distribute the helium to the appropriate components. It is also necessary to modify the transfer function of the engine feedlines to prevent coupling which would lead to catastrophic thrust oscillations (the pogo phenomenon). To this end, a device known as a pogo attenuation system is installed and used on these feedlines. Progress is also currently being made with regard to simplification, cost reduction, improved processes for RLV operation, and increased reliability for all equipment contributing to the propulsion.

The umbilical plates and junctions between the ground and the RLV, disconnected just before or just after liftoff, are sophisticated devices that may be improved to allow for fast reconnection, and will be an eventual requirement for RLVs. Pressure-regulating systems have already undergone changes with the move to regulators with go/no go control valves for high flow rate pressurization, as on the Ariane 5 tanks. Today, research is conducted on electronically controlled pressure regulators for precise control of low flow rates, high pressures for control systems, and pressurizing valves. Several of these more advanced components currently under development are shown in Fig. 14.

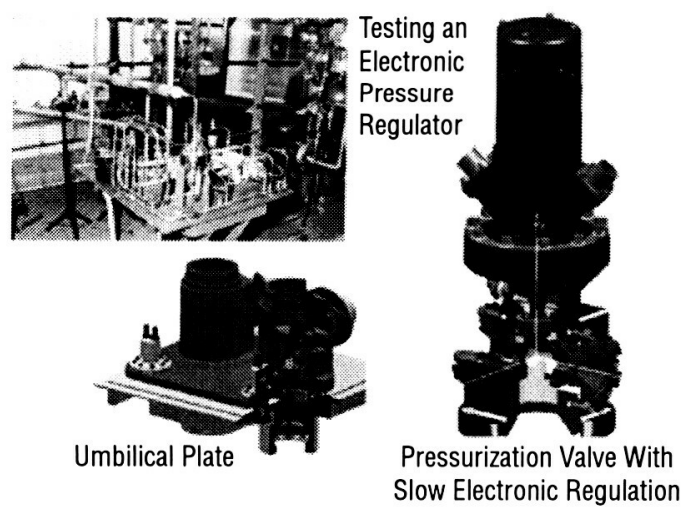

Fig. 14. Toward a new generation of propulsion systems.

Instrumentation is required everywhere on an RLV, and even though the space propulsion sector does not have a volume of activity that would allow the development of totally new measurement technologies, it still leads to research and development work intended to adapt these technologies to conditions specific to cryogenic rocket engines. On the engine, it must be possible to install pressure, temperature, vibration, displacement, and rotation sensors as unobtrusively as possible. New optical fiberbased technologies are being developed for this purpose. They also allow sensitive measurements, such as the $\mathrm{LH}_{2}$ content or leakage in the engine environment, with much shorter response times than with spectrometric measurement. An example of such a device is shown in Fig. 15.

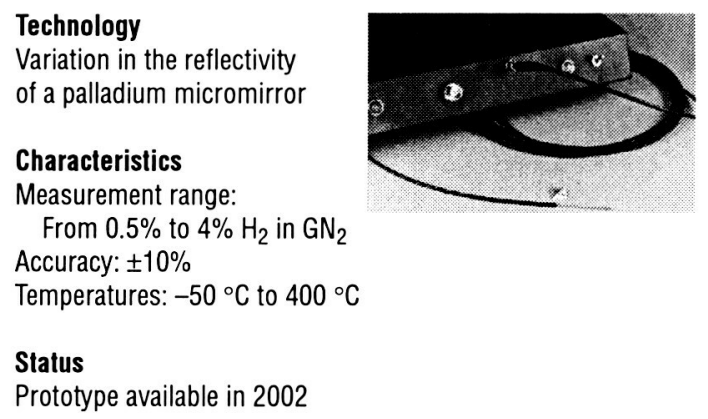

Fig. 15. Optical $\mathrm{LH}_{2}$ detector.

Eventually, RLV engines will be equipped with instrumentation and a microsystem for processing the condition of the engine, giving real-time indications to the computer managing engine operations, as well as for ease of maintenance activities between successive flights of the RLV. But even today, automated diagnostic systems are being used more and more to analyze engine ground tests or in-flight measurements in a faster, more economical way.

\section{SOLID PROPELLANT PROPULSION}

In past decades, solid propulsion has played a major role in the development of the western world launchers. Today's heavy lift launchers almost always use a combination of liquid and solid motors. ${ }^{1}$

The limited specific impulse of solid rocket motors (SRMs) is well known, but SRMs are a cost-effective way to generate the high thrust and high single burn total impulse required for lower stages of heavy lift launchers. Today, the community involved in space activities is looking for the best ways to reduce the cost of access to space.

A question for space agencies and prime contractors is what role there will be for solid propulsion for the future and where to invest in development of related technologies. The fact is that the RLV concept studies leave no visible room for solid propulsion. However, the application of SRM to the Earth-to-orbit launch systems will exist for a long time, as well as for strategic missiles. Therefore, the research and technology effort concerning 
SRMs must be oriented and conducted for this technology to keep its place and to contribute to the general objectives of development and production costs reduction as well as performance and reliability improvements.

Taking into account the technologies developed in the 1990's, the large SRMs (segmented or not) of medium or heavy launchers will be characterized by the use of Filament-wound carbon cases, reducing the inert mass and cost, and leading to increased operating pressure; stateof-the-art propellant HTPB type since this is the existing lower cost raw material system, but operating at higher pressures and produced with more cost-efficient processes; lighter thermal insulations and lower cost bonding systems; and nozzles designed with low-cost materials.

\section{$\underline{\text { A New Optimization }}$}

For composite cases, the use of carbon fibers in a monolithic booster leads to a performance factor (PV/ mgo), expressed in $\mathrm{km}$, equal to 45 , to be compared with $30 \mathrm{~km}$ for Kevlar and $20 \mathrm{~km}$ for glass used 20 years ago. The use of carbon cases leads to large gains in structural ratios, particularly compared to steel.

Considering the overall performance gain, an increase in pressure must also be obtained. For a stage operating at ground level with a limited diameter of the exit cone, it is the only way to increase the specific impulse, an increase which is of paramount importance for the overall performance.

For the same outlet cross section, a 3-MPa pressure increase leads to a specific impulse gain of $\approx 10 \mathrm{~s}$, and thereby to a payload gain of nearly $10 \%$ on an Ariane $V$. This increase in pressure also allows a reduction of the nozzle throat diameter leading to a smaller nozzle.

\section{More Controlled and Efficient Propellant Production}

The modern solid propellant production motor still uses the conventional batch mix-cast process. In recent times, continuous production processes have been implemented for various applications. For example, a continuous production line of a (thermosetting) composite propellant for an airbag based on twin-screw extrusion has been operating very successfully and efficiently at SNPE for more than 4 years. Today, this unit produces more propellant than that produced for strategic and tactical systems combined. This experience is very useful in developing a continuous mix-cast system for space boosters when the production quantities justify the investment. A pilot-sized unit has already demonstrated the feasibility of producing the present Ariane $\mathrm{V}$ propellant formulation with cost savings for the propellant on the order of $30 \%$. This process also allows the use of faster curing systems, which means shorter production cycles. ${ }^{2}$
The variations in ingredient quantities involved in the active and sensitive part of mixing is greatly reduced over batch operations, which means better safety and reduced costs. This could also be useful in the future with the use of more energetic ingredients in the propellant.

Another important development is a $3 \mathrm{D}$ numerical simulation of the propellant casting. A 3D code can be used to calculate the real burnback evolution and the resulting pressure and thrust curves for precise prediction and operating parameter control (Fig. 16).

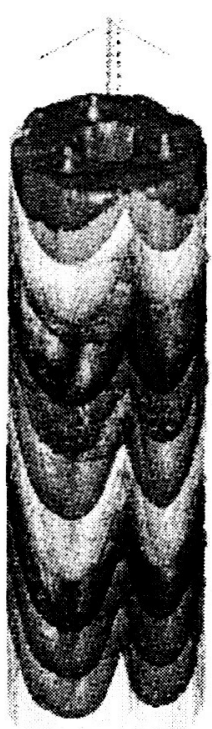

\section{Fig. 16. Numerical simulation of propellant grain casting with ten batches and three casting points.}

Yet another development is related to the simulation of process influence on ballistics through the rheology of particle suspension which constitutes the propellant. Rheology and particle segregation under shear explain such effects as the so-called "hump" and "knitlines" effects-during this flow, particles tend to segregate according to their size and to the shear field. A direct consequence of these effects is the local rate of combustion modification with possible consequences on the pressure curve and on the thermal insulation erosion. Solving the Navier-Stokes equations, in which a viscosityconcentration module is introduced, leads to a complete description of the grain burning characteristics which can be coupled with the previous model to reach the ultimate goal-that no more "potentiometric" or semi-empirical parameters, such as the so-called scale or hump factors, will be necessary for new designs; critical erosion zones will be identified and modified with a reduction of the number of tests. The effect of any variations in propellant processing can also be quantified. 


\section{Modern and Future Nozzle Technologies}

Cost reductions can be realized by reducing the number of components in a motor. For example, on an Ariane 5 MPS nozzle, a major parts reduction from 20 to 13 will be realized. For the longer term, research and technology efforts will result in new materials and architectures, such as thrust vector actuation items.

For a new generation of space motor nozzles for space application, Snecma Propulsion Solide is studying a new flex-seal architecture with a low torque value including its thermal insulation to lower the overall cost; a low-cost aft exit cone manufactured with a structural carbon/ phenolic composite material allowing reduction of nozzle mass and inertia; and a new carbon reinforcement for the throat to reduce its direct and associated costs (Fig. 17).

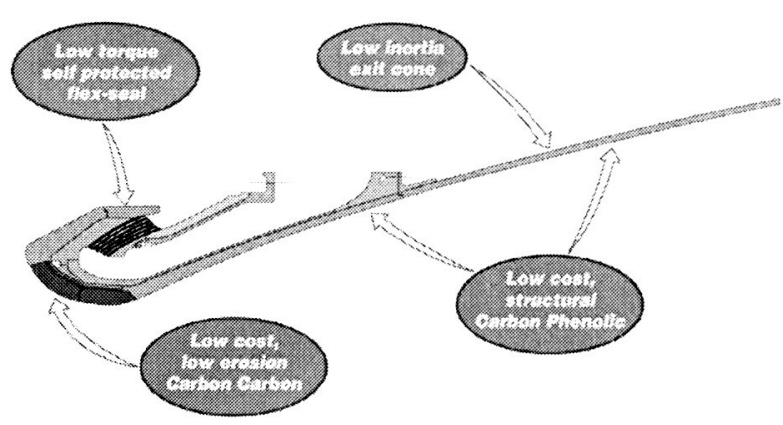

Fig. 17. Low torque and low-cost nozzle design.

\section{Low-Cost Throat Carbon/Carbon}

Current carbon/carbon Ariane 5 throat material is based on NOVOLTEX ${ }^{\circledR}$ reinforcement which is manufactured with polyacrylonitrile (PAN) fiber after a preliminary oxidation treatment. These fibers are transformed to fabrics which are then used to form annular blanks with a 3D reinforcement. A thermal treatment is then applied to fulfill the fiber transformation in pure carbon with a fiber ratio of $28 \%$. The proposed new reinforcement called MULTIREX is manufactured directly from commercial carbon fibers with a fiber ratio of $35 \%$.

This material reinforcement will allow reduction of direct manufacturing and associated costs (less manufacturing investments and purchase support). It presents better mechanical performances and will enhance component reliability. Its lower erosion accrues from a higher fiber ratio (35\% versus $28 \%$ for NOVOLTEX), and will increase launcher performance, thanks to a better average specific impulse. Small-scale components have been tested in motors and large-scale industrial validation is underway.

\section{Low Torque Flex-Seal}

Two evolutions can be implemented to reduce the flex-bearing torque value of a conventional-type nozzle. The first one is to change the well-known natural rubber currently used, which presents a high shear modulus by isoprene or silicone-based rubber with lower shear modulus. Preliminary material activities have shown interesting potential.

The second one is to design a new architecture leading to a reduced torque by evolving from the current cylindrical shape to a new conical shape with highly canted shims. Such a design can be mastered by powerful 3D calculation tools. Preliminary designs indicate that the torque value could be reduced by at least a factor of 2 , while keeping the same safety margins.

There are several advantages of reducing the torque generated by the flex-seal. First, it allows reduction of all the 3D load cases that the nozzle structures must withstand, leading to reduced loads stresses on mechanical joints and the bonding between housing and thermal components. The second and main point is that it allows reduction of the thrust vectoring and control (TVC) subsystem torques.

This small reduction reduces the size of actuators and power source with, for example, a smaller hydraulic system (lower price and mass). A larger reduction allows a change in TVC concept, such as turning to electrohydraulic systems or electromechanical concepts with potential larger benefits for the launcher.

\section{Self-Protected Flux Seal}

An improvement under evaluation is to adapt the concept of bearing with composite shims including extensions at the chamber sides as thermal protection. This concept consistently reduces the number of parts and the costs (Fig. 18). Currently used on SRMs for strategic application with burning time near 1 minute, this concept is also applied on SRMU nozzles requiring a burning time twice as long.

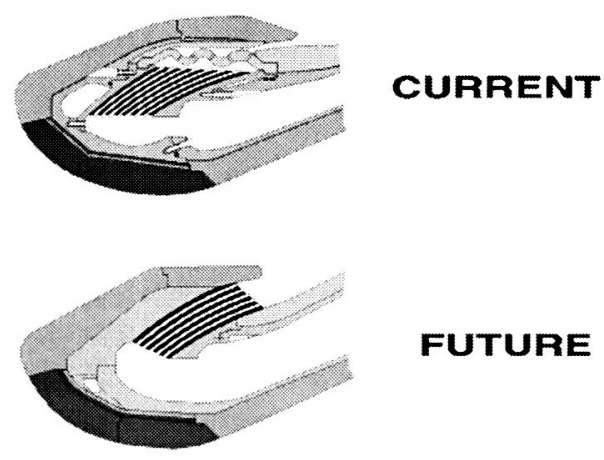

Fig. 18. Self-protected flex-seal concept. 


\section{SRM Technologies for 2025 and Later}

The progress expected in structural, thermostructural, and energetic materials technologies will translate into new improvements of SRMs during the period 2020 to 2030. A demonstrator using many of the following technologies may be tested in 2025 .

\section{Totally New Molecules of Very High Energy}

The discovery of new compounds has been announced recently. Besides the synthesis of octanitrocubane whose energy density could be higher than the energy density of HNIW if the proper solid isomorph is found, compounds of the polynitrogen type are being actively investigated because they promise, on the basis of theoretical calculations, access to very high levels of specific energy.

The formation enthalpy of RDX is $20 \mathrm{Kcal} / \mathrm{mole}$; 98 for HNIW; 140 for octanitrocubane; 168 for DNAF, a nitrogen-rich molecule synthesized in France; 345 for the recently synthesized cation $\mathrm{N} 5+$ (but lower if combined with a low energy anion); 190 for $\mathrm{N} 4$, a compound not yet synthesized but the subject of intense research in Sweden; and 450 to 500 for N8. The decomposition of $\mathrm{N} 4$ or N8 would give specific impulses in the range of 480 to $550 \mathrm{~s}$, but with temperatures higher than $5000 \mathrm{~K}$. Hence, more moderate combinations must be found for thermal and stability tolerance and survival.

\section{MORE ADVANCED ENGINES}

In all the areas mentioned above, research and technology development activities lead to improvements or technological breakthroughs on particular capabilities, or even on whole rocket engine subsystems. These improvements have the potential to make engines more efficient, more reliable, and less costly for decades to come. But are there certain potential technological breakthroughs that radically advance the whole engine, such as with aircraft when piston and propeller engines were replaced by jet engines. There are many different ways to produce thrust by ejecting a fluid at very high velocities and some ways without ejecting pure fluid jet. Electric engines, such as ion, plasma, and arc jet, are completely different from chemical rocket engines. In a chemical rocket engine, the energy is supplied purely by a chemical reaction. In electric propulsion, there is separation between the source of the acceleration energy and the matter to be ejected. So as long as electrical power remains relatively limited with heavyweight sources, electric engines will produce the low thrust levels we see today $(0.1$ or $3 \mathrm{~N})$. Their use is limited to in-space propulsion, where the T/W ratio is of relatively little consequence. The application of electric propulsion to telecommunication satellites or space probes is a technological advancement that has been ongoing for the last few years. A high-power nuclear electric propulsion spacecraft concept is illustrated in Fig. 19.

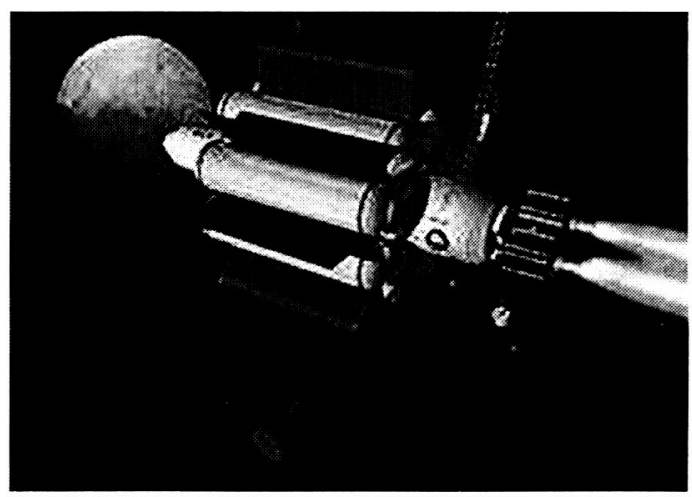

Fig. 19. Toward high-power electrical propulsion.

For several decades, great hopes were based on combined air-breathing and rocket engines that would initially use air as an oxidizer during the atmospheric phase of the flight. Many combinations of engine cycles are possible in the course of this atmospheric stage, such as jet engine followed by ramjet engine (with subsonic, then supersonic combustion), then rocket engine or air dilution rocket, then ramjet engine, then rocket. If the work of the launcher is split between two stages, we get solutions with fewer combinations, such as jet engine/ramjet engine for the first stage and traditional rocket engine for the second stage, or jet engine (able to reach Mach 4) for the first stage and ramjet engine/rocket for the second stage. In all these cases, propulsion becomes more complex and therefore less reliable than traditional rocket propulsion. The weight of the engines and propulsion systems is also generally greater; i.e., a lower T/W ratio. An example of a design approach for a combined cycle booster engine is illustrated in Fig. 20.

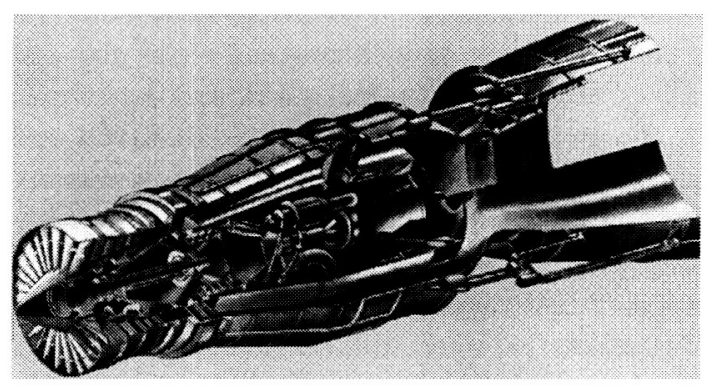

Fig. 20. Design study for jet-rocket/ramjet/scramjet/ rocket engine running in air-breathing mode from Mach 0 to 7. 
For such innovative solutions to be applied, the advantages, such as lighter weight launchers, more flexibility in the geographic requirements for launch installations due to the possibility of a cruise phase before final launch, and the resulting economic benefits, must outweigh the disadvantages. Technological progress will eventually make these modes of propulsion possible, but the same progress will also apply to traditional launchers and rocket engines. For space launchers, studies and even tests are regularly conducted to see if the advent of these modes of propulsion is becoming more readily achievable. However, it is likely that technology evaluation and eventual maturation of a combined cycle-powered vehicle will not occur for at least 20 years. But this combined airbreathing and rocket propulsion has already found some application to small missiles. An artist's concept of a future combined cycle engine-powered RLV is shown in Fig. 21.

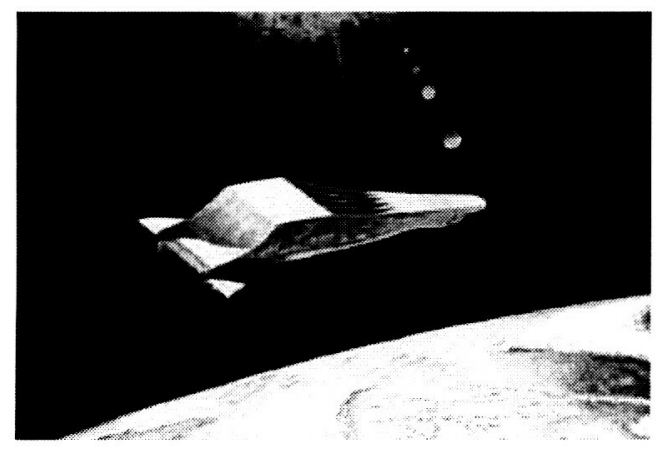

Fig. 21. Toward orbital single stage thanks to combined air-breathing/rocket propulsion.

The first decade of the 21 st century should provide accelerated progress in technologies for these combined cycle engine RLVs. An investment strategy for the next decade was developed, approved, and partially funded just before the beginning of this decade, providing an auspicious start. The strategy includes an incremental approach leading to successively more complex, more integrated demonstrations, progressing from foundation technologies, components, subsystems, and systems in ground test and then flight. In flight, the demonstration vehicles steadily expand the envelope in increasingly demanding conditions with higher fidelity toward goal configurations.

Implementation of NASA plans in the U.S. just after mid-decade will enable preparation of the first flight-like scramjet propulsion system integrated with a hypersonic lifting body airframe for flight test. The X-43a demonstrator vehicle will have been tested in flight and will allow timely incorporation of its database and lessons learned into airframe, propulsion, and flight demonstration activities that will be in the midst of detailed design and early in ground test demonstration. The configurations for turbine-based combined cycles (TBCC), rocket-based combined cycles (RBCC), and scramjets will be understood with substantial refinement; plans will be in place then for subsequent builds of the ground demonstration engines to continue to mature the technologies so that the propulsion system characteristics are demonstrated to progress toward the goals.

At the end of the decade the U.S. will have the potential to fly at least one of the combined cycle propulsion flight demonstration systems in a relatively small-scale demonstrator vehicle known as X-43b. A downselect for which the combined-cycle concept goes into flight demonstration first will have occurred just after middecade to enable the program to proceed with development of the X-43b propulsion system. In addition, a wealth of ground test data at laboratory scale of components and propulsion systems, coupled with X-43a and X-43c flight data and the progress made in advanced development and development for 2 nd Generation RLVs, will result in far more insight into the "vision," "goal," or "objective" design concepts that might comprise an operational combined cycle engine RLV.

Above all, very low-density, high-temperature capable, high-strength actively and passively cooled materials with their associated structural architecture will be critical. It can be projected that toward the end of the next decade, ceramic-based systems will find their way into more critical components and applications, and will likely be one of the breakthroughs that can be touted in a similar paper written 10 years from now. Advanced metallics with properties substantially improved over those of today's operational materials will be employed extensively in the test activity of advanced RLVs. Another possibility for certain types of structures will be higher temperature, polymer-based materials.

Also, by the end of the next decade, another revolution in design tool and design capability should have occurred. Broader and deeper understanding of physics through advanced sensing techniques, combined with improved numerical and simulation methods, health management and selected experimentation and technology demonstration, should greatly increase the quantity of design options that can be addressed without increasing the number of iterations that must be accomplished. Furthermore, the level of detail and fidelity available with future modeling and analytical capabilities will reduce the uncertainties in the results.

In summary, by the end of this decade, pieces of data should be available that will allow movement toward the first integrated systems that incorporate all the key technologies and demonstrate RLV total end-to-end mission, operational, safety, and economic performance potential. 
Yet, another revolutionary approach that is being investigated is that of pulsed-detonation engines in which combustion is not continuous. The thermodynamic conditions are changed (combustion at iso-volume and not at iso-pressure) and this engine can potentially eliminate the need for turbopumps used to pressurize the propellants to feed the combustion chamber. In addition, pulsed explosive combustion operation is also applicable to airbreathing propulsion (missiles, jet engine afterburning). On the other hand, the materials, controls, and valving issues (based on the induced stresses and cycle frequencies) could present some daunting future technology development challenges. A pulsed detonation engine concept is illustrated in Fig. 22.

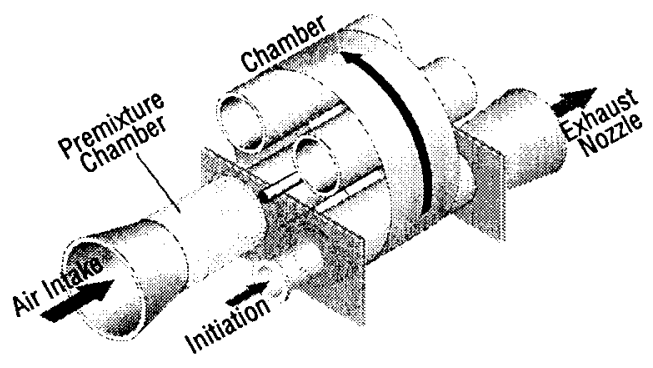

Fig. 22. Pulsed detonation engine.

\section{IN-SPACE TRANSPORTATION}

\section{Introduction and Chemical}

Technology advances for in-space transportation have occurred in three primary categories: advanced materials, engine designs and propellants for chemical propulsion, and development and demonstration of electric propulsion and soon-to-be-flown "propellantless" systems. These advancements are depicted in Fig. 23.

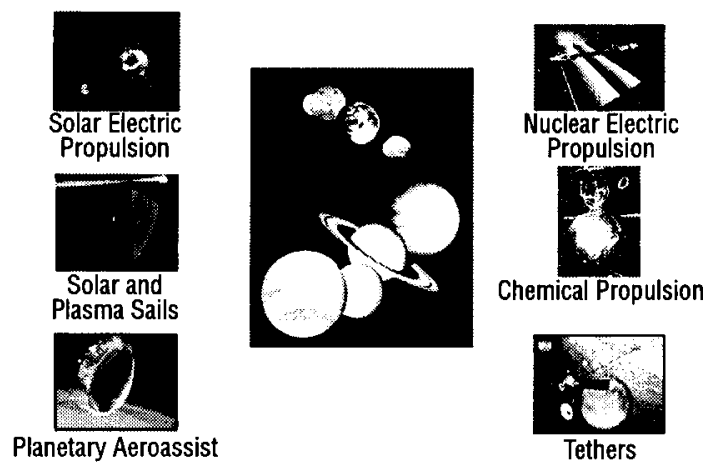

Fig. 23. In-space propulsion systems.

In chemical propulsion, development of iridiumrhenium chambers pioneered by NASA and industry was begun in the 1980's. During the 1990's, the technology was brought from a low TRL level proof-of-concept maturity to operational use. This provided a substantial advancement in performance parameters for monopropellant and bipropellant systems, offering long life at increased specific impulse (323 s in qualification testing) ${ }^{3}$ The first flight occurred in 1999. In addition, major advancements in spacecraft dual-mode propulsion systems; i.e., using hydrazine as both bipropellant fuel and as a monopropellant in the same system, have enabled higher spacecraft performance and operational benefits, such as for the Chandra $\mathrm{x}$-ray telescope.

Although not yet implemented in a flight program, substantial progress has been made in HAN-based monopropellant spacecraft propulsion thrusters which are considered to be relatively nontoxic and have acceptable specific impulse and good density impulse characteristics. This is important because increasingly strict safety and environmental regulations as well as operations costs make it steadily more difficult to utilize traditional monopropellants. During the 1990's, stable HAN-based monopropellant mixes with laboratory thrusters using catalytic ignition were demonstrated with over $8000 \mathrm{~s}$ of cumulative operation on a single catalyst/thruster combination. ${ }^{4,5}$ The result was accomplished by an industry/NASA team. The results will likely open the door to further development and eventual adoption for spacecraft use.

\section{Electric}

Substantial gains occurred in electric propulsion during the 1990's. Electric propulsion has very low thrust but extremely high specific impulse. Appropriate use through mission design, and availability of adequate spacecraft power, along with the advances made in thruster technology, has brought widespread application within reach due to the substantial competitive advantage, cost reduction, or mission-enabling advantages provided. Often, electric propulsion can mean the difference in vehicle class, substantial addition to payload mass, or feasibility of a deep space exploration mission. Electric propulsion can be categorized into three types that relate to the physics of the acceleration mechanism employed: electrothermal, electrostatic, and electromagnetic, all of which are experiencing increased technology readiness, programmatic acceptance, and flight applications.

The first major breakthrough of electric propulsion into broad spacecraft use was with electrothermal systems. Focused development of high-performance arc jet technology was begun by NASA in 1991. The technology was adopted by the propulsion industry and commercial spacecraft designers soon after the technology development progress and mission benefits became 
apparent. The result was that in 1996, three commercial communications satellites were launched with hydrazine arc jet systems for North-South stationkeeping. ${ }^{6}$ Another significant advancement was to employ dual-mode propulsion systems that could use hydrazine propellant for both chemical and electric propulsion. Beyond the thruster technology, the increase in spacecraft available power was a major factor in enabling the introduction of electric propulsion.

Electrostatic systems, which are becoming more important for future space missions, went through dramatic and exciting advances in the 1990's. Hall thrusters achieved substantial advances, including becoming operational for flight use. A major effort was conducted during the early and mid 1990's to bring Russian developments to the west which culminated with the first flight of a Hall thruster on a western spacecraft for the STEX technology demonstration mission. ${ }^{7}$ NASA led these efforts for the Department of Defense. Widespread commercial development of thrusters ${ }^{8}$ was given impetus by all the proposed broadband satellite constellations and substantially aided by use of the technology transfer results plus NASA-funded efforts as a basis.

Ion propulsion for deep-space exploration missions gained a large increment of maturity with the development and successful flight of the NASA Solar Electric Propulsion Technology Application Readiness (NSTAR) program..${ }^{9}$ NSTAR was the first interplanetary spacecraft to use ion thrusters as main propulsion. It was flown on the Deep Space-1 spacecraft under the new millennium program. Launch occurred in 1998. The NSTAR engine uses Xenon propellant, has a 30-cm optics diameter, and was operated at $0.5-2 \mathrm{~kW}$ in flight. The engine was designed for $8000 \mathrm{hr}$ life, and has performed well in flight, now having demonstrated in excess of $20,000 \mathrm{hr}$ of space operation. It must be noted also that commercial communication satellites utilize ion propulsion for stationkeeping. The first of these was launched in 1997.

Another significant advancement for electric propulsion was achieved through development of the plasma contactor for the International Space Station (ISS). ${ }^{10}$ This device utilizes the same hollow cathode that is required for neutralization in an electrostatic propulsion system. The station hollow cathode assembly, designed, developed, built, and tested by NASA accumulated 27,800 $\mathrm{hr}$ of operation during life test, demonstrating very long life for an essential propulsion system component. ${ }^{11}$

\section{Propellantless}

Advancements have also been made in the so-called "propellantless" categories that include solar sails and tethers, as depicted in Fig. 24. A series of systems tests

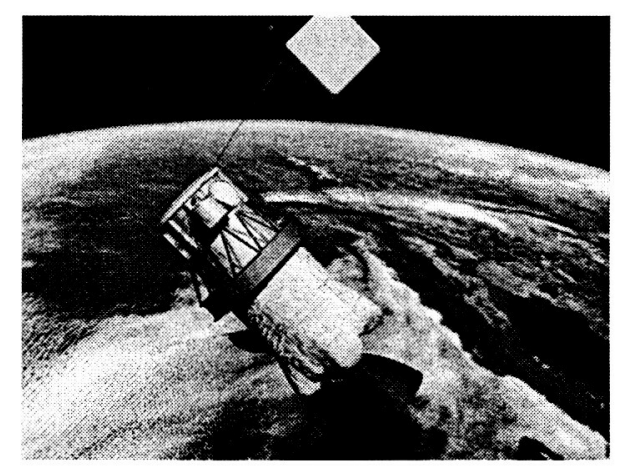

Fig. 24. Tether being used to maneuver a satellite in space.

on a propellant-free propulsion technology have recently been completed at MSFC. The Propulsive Small Expendable Deployer System (ProSEDS) is a tether-based propulsion system that draws power from the space environment around the Earth, allowing the transfer of energy from the Earth to the spacecraft. Electrodynamic tethers used for the propulsion in low-Earth orbit and beyond could significantly reduce the weight of upper-stage rockets used to boost spacecraft to higher orbit. And because they require no propellant, electrodynamic tethers substantially reduce spacecraft weight, providing a cheap, efficient method of reboosting the orbits of spacecraft and potentially the ISS.

An electrodynamic tether, which consists of a long, thin wire deployed from an orbiting satellite or vehicle, uses the same principles as electric motors in many household appliances and automobile generators. When a wire moves through a magnetic field, an electric current results. As this current flows through the wire, it experiences a push from any external magnetic field. The force exerted on the tether by the magnetic field can be used to raise or lower a satellite's orbit, depending on the direction of the current's flow.

As mentioned earlier, another category of propellantless propulsion is solar sails. Solar sails use photon "pressure" of force from the Sun on thin, lightweight reflective sheets to produce thrust. The net force or thrust on the solar sail is perpendicular to the surface, which is the result of a force tangential to orbit and a force perpendicular to the orbit caused by the reflective sunlight, as shown in Fig. 25. Ideal reflection of sunlight from the solar sail surface produces $9 \mathrm{~N} / \mathrm{km}^{2}$ at $1 \mathrm{AU}$.

\section{The Next Decade}

Advanced higher energy chemical propulsion still offers a unique combination of features that for some mission requirements have no substitutes. It is likely that green (nontoxic) propellants will continue to be under 

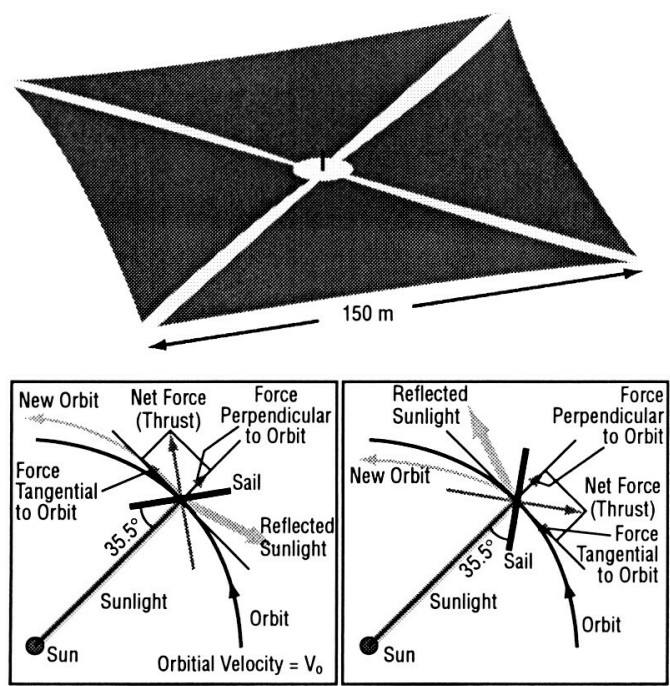

Fig. 25. Solar sail and how thrust is derived from the reflection of the sunlight on the solar sail.

technology development and begin to be introduced into at least some operational missions. Planetary exploration will likely demand the extension of existing technologies to meet the unique needs of planetary space transportation from surface to orbit.

Power availability for spacecraft will continue to increase, affording the opportunity to substitute electric propulsion for chemical propulsion for main orbit transfer with acceptable transit times. Taking advantage of higher power capability in a most advantageous fashion will demand increasing power capability from the thrusters with high efficiency. In both Hall and ion systems, 10-kW maximum power thrusters are under technology development. Planetary exploration, as well as multipurpose Earth-orbit thrusting, requires a wide operating range at acceptable efficiency. In the case of ion systems utilizing solar power for planetary exploration, the power available is steadily reduced as the distance from the Sun increases, placing important operational demands and contraints on the designs.

Another trend likely to eventually emerge will be the availability of advanced power sources that lead to the capability to perform ambitious missions that require very high power, very high specific impulse conditions. Thrusters to meet this demand will likely be demonstrated, possibly with a substantial level of maturity, that might provide a point of departure for flight demonstration in the second decade of the century.

In theory, the nuclear-thermal engine, in which a fluid ejected by a traditional nozzle is heated by a nuclear reactor, could be used to leave the Earth. However, the ejected fluid is radioactive due to the erosion of the nuclear fuel components, and its use in the atmosphere is therefore highly improbable with today's environmental standards. Examples of nuclear energy-powered propulsion options are shown in Fig. 26.

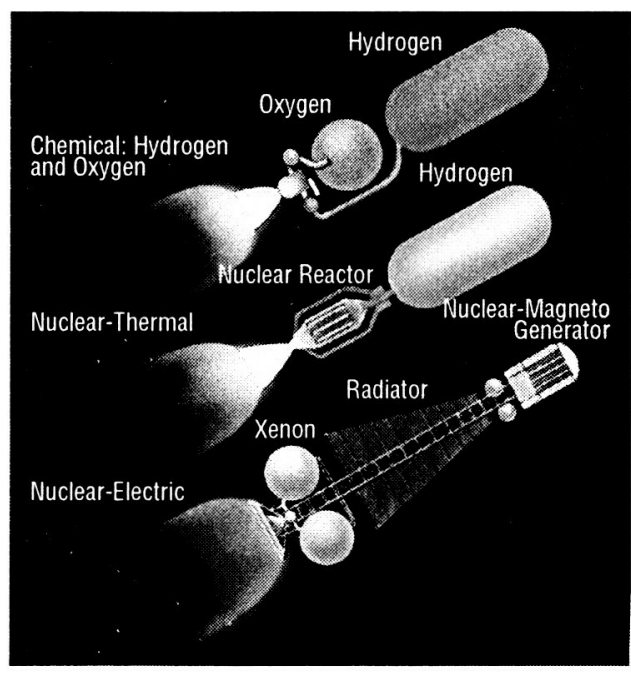

Fig. 26. Chemical, nuclear-thermal, and nuclearelectric propulsion.

Traditional liquid or solid rocket engines will therefore still be around for a long time. Improvements in chemical propellant energy is still a strong possibility, more so for solid propulsion than for liquid propulsion. For the latter, the hydrogen/fluorine combination is superior to the $\mathrm{LH}_{2} / \mathrm{LO}_{2}$ combination. Tests were conducted in the 1960's, but major safety considerations and limitations have prevented the development of fluorine oxidizer engines. Also, studies have been conducted on the use of small amounts of $\mathrm{LH}_{2}$ in high-energy density forms (metallic or atomic hydrogen). Their applications are still very remote because of today's technology issues.

In the course of the next 10 years, a major improvement that could be applied to propulsion systems is the increase in $\mathrm{LH}_{2}$ and $\mathrm{LO}_{2}$ density by subcooling the propellants. Eventually this subcooling may reach the level where a "slush" mixture of "semi" solid and liquid is obtained. These improvements do not significantly affect the engine performance, but rather the mass fraction/structural efficiency performance of the RLV, by allowing a reduction in tank weight. It should be pointed out that studies and tests (on a very small scale) are in progress for a coupling of liquid and solid propulsion; i.e., the $\mathrm{LH}_{2}$ and the $\mathrm{LO}_{2}$ can be blended and cooled until they solidify. This produces a "solid" booster with solid hydrogen and oxygen combining the simplicity of the solid and the performance of the liquid. However, propellants other than $\mathrm{LH}_{2}$ and $\mathrm{LO}_{2}$ would appear to be more suitable to this application in a mixture solidified by cooling.

It would certainly be very interesting to have a new presentation in 20 years' time to see if some of these new modes of propulsion have come to fruition. 


\section{REFERENCES}

1. Davenas, A., Boury, D., Calabro, M., D'Andrea, B., McDonald, A. J., "Solid Propulsion For Space Applications: A Road Map," 51st International Astronautical Congress, Rio de Janeiro, Brazil, October 2000.

2. Boury, D., "Modern Technologies For Large Space Solid Rocket Motors," 50th International Astronautical Congress, Amsterdam, the Netherlands, October 1999.

3. Stechman, C., Woli, P., Fuller, R., and Colette, A., "A High Performance Liquid Rocket Engine for Satellite Main Propulsion," 36th Joint Propulsion Conference, Huntsville, AL, July 2000.

4. Meinhardt, D., Christofferson, S., Wucherer, E., and Reed, B., Performance and Life Testing of Small HAN Thusters," 35th Joint Propulsion Conference, Los Angeles, CA, June 1999.

5. Wucherer, E. J., Christofferson, S. S., and Reed, B., "Assessment of High Performance HANMonopropellants," 36th Joint Propulsion Conference, Huntsville, AL, July 2000.

6. Zube, D. M., Lichon, P. G., Cohen, D., Lichtin, D. A., Bailey, J. A., and Chilelli, N. V., "Intitial OnOrbit Performance of Hydrazine Arcjets on A2100 TM Satellites," 35th Joint Propulsion Conference, Los Angeles, CA, June 1999.
7. Sankovic, J., Caveny, L., and Lynn, P., "The BMDO Russian Hall Electric Thruster Technology (RHETT) Program: From Laboratory to Orbit," IEPC-97-2917, July 1997.

8. Randolph, T., "Overview of Major U.S. Industrial Programs in Electric Propulsion," AIAA-99-2160, June 1999.

9. Polk, J. E., Kakuda, R. Y., Anderson, J. R., Brophy, J. R., Rawlin, V. K., Patterson, M. J., Sovey, J., and Hamley, J., "Validation of the NSTAR Ion Propulsion System on the Deep Space One Mission: Overview and Initial Results," 35th Joint Propulsion Conference, Los Angeles, CA, June 1999.

10. Cikanek, H. A. and Sackheim, R. L., "Space Transportation Technology Development at the U.S. National Aeronautics and Space Administration (NASA)," 6th International Symposium, Propulsion for Space Transportation of the XXIst Century, Versailles, France, May 14-17, 2002.

11. Sackheim, R. L., and Cikanek, H. A., "Evolution of Propulsion Requirements for Future Space Transportation Systems," 6th International Symposium, Propulsion for Space Transportation of the XXIst Century, Versailles, France, May 14-17, 2002. 